\title{
On-orbit radiometric calibration of SWIR bands of TANSO-FTS onboard GOSAT
}

\author{
Y. Yoshida, N. Kikuchi, and T. Yokota \\ National Institute for Environmental Studies, 16-2 Onogawa, Tsukuba 305-8506, Japan \\ Correspondence to: Y. Yoshida (yoshida.yukio@nies.go.jp) \\ Received: 29 May 2012 - Published in Atmos. Meas. Tech. Discuss.: 10 July 2012 \\ Revised: 21 September 2012 - Accepted: 4 October 2012 - Published: 26 October 2012
}

\begin{abstract}
The Greenhouse gases Observing SATellite (GOSAT) was launched on 23 January 2009 to monitor global distributions of carbon dioxide and methane. The Thermal And Near-infrared Sensor for carbon ObservationFourier Transform Spectrometer (TANSO-FTS) onboard GOSAT measures the short-wavelength infrared (SWIR) spectra. Radiometric accuracy directly influences the accuracy of the retrieved greenhouse gas concentrations. From a 2.5-yr retrieval analysis of GOSAT data, we found that the minimum of the mean-squared value of the residuals (the difference between observed and fitted spectra) and the radiance adjustment factor (one of the ancillary parameters to be retrieved with the gas concentrations for adjusting the radiance level between the bands) changed with time, possibly due to inaccurate degradation correction. In this study, the radiometric degradation of TANSO-FTS was evaluated from the on-orbit solar calibration data and modeled as a function of time and wavenumber for each spectral band. The radiometric degradation of TANSO-FTS Band 1 (centered at $0.76 \mu \mathrm{m}$ ) after the launch was found to be about 4 to $6 \%$, varying with wavenumber, whereas the other two bands (Band 2: $1.6 \mu \mathrm{m}$ and Band 3: $2.0 \mu \mathrm{m}$ ) showed about $1 \%$ degradation and small wavenumber dependency. When we applied the new degradation model in the retrieval analysis, the above-mentioned issues disappeared.
\end{abstract}

\section{Introduction}

Atmospheric carbon dioxide $\left(\mathrm{CO}_{2}\right)$ and methane $\left(\mathrm{CH}_{4}\right)$ are well-known anthropogenic greenhouse gases. The global monitoring of these gases from space is expected to improve our knowledge of the global distribution and seasonal cycle of the carbon flux (Rayner and O'Brien, 2001; Chevallier et al., 2007, 2009; Hungershoefer et al., 2010; Takagi et al., 2011).

The Greenhouse gases Observing SATellite (GOSAT) was launched on 23 January 2009 to monitor the global distributions of $\mathrm{CO}_{2}$ and $\mathrm{CH}_{4}$ from space. It is equipped with two instruments: the Thermal And Near infrared Sensor for carbon Observation-Fourier Transform Spectrometer (TANSO-FTS) and the Cloud and Aerosol Imager (TANSO-CAI) (Kuze et al., 2009). The TANSO-FTS is the main instrument to observe $\mathrm{CO}_{2}$ and $\mathrm{CH}_{4}$. It measures solar light reflected from the Earth's surface in the short-wavelength infrared (SWIR) region (centered at 0.76, 1.6, and $2.0 \mu \mathrm{m}$; TANSO-FTS Bands 1,2 , and 3 , respectively) with two orthogonal linear polarizations, designated "P" and "S". It further collects thermal radiation from the Earth's surface and atmosphere in the thermal infrared (TIR) region (5.5 to $14.3 \mu \mathrm{m}$; TANSO-FTS Band 4). Column-averaged dry-air mole fractions of $\mathrm{CO}_{2}$ and $\mathrm{CH}_{4}\left(\mathrm{XCO}_{2}\right.$ and $\left.\mathrm{XCH}_{4}\right)$ retrieved from SWIR spectra have been released as the GOSAT SWIR Level 2 product (SWIR L2; Yokota et al., 2009; Yoshida et al., 2011). Other retrieval algorithms have also been developed and applied to the GOSAT SWIR observations (Oshchepkov et al., 2011; Butz et al., 2011; Parker et al., 2011; O’Dell et al., 2012; Crisp et al., 2012; Schepers et al., 2012). One of the major error sources of the retrieved $\mathrm{XCO}_{2}$ and $\mathrm{XCH}_{4}$ is the optical path modification due to atmospheric light scattering. The strength of the optical path modification differs with wavenumber, because it depends on both the amount of scattering particles and the surface reflectance. Therefore, accurate radiometric calibration of TANSO-FTS is needed to retrieve accurate estimates of $\mathrm{XCO}_{2}$ and $\mathrm{XCH}_{4}$. 


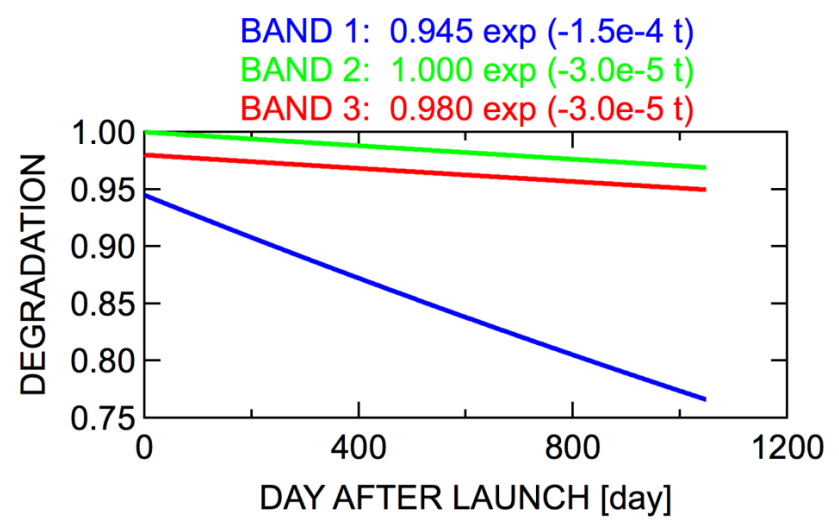

Fig. 1. TANSO-FTS degradation model used in the SWIR L2 version 01.xx retrieval analysis.

Currently, most of the GOSAT SWIR retrieval algorithms use the simple degradation model proposed by Kuze at the Japan Aerospace Exploration Agency (JAXA; A. Kuze, personal communication, 2010; Fig. 1). However, this degradation model predicts faster degradation than the actual one, especially for Band 1 (Kuze et al., 2011, 2012). Furthermore, the degradation of each band is modeled as a function of time, but the model does not take the polarization and wavenumber dependencies into account. From an analysis of $2.5 \mathrm{yr}$ of retrievals using SWIR L2 version 01.xx (Yoshida et al., 2011), we found two time-dependent issues (see next section for details), which may be related to the degradation model. In this study, we re-evaluated the TANSO-FTS degradation using the on-orbit solar calibration data (i.e., the spectral radiances) and evaluated the wavenumber and polarization dependencies more precisely.

\section{Time-dependent issues found in the SWIR L2 version 01.xx retrieval}

The following two issues were found in the SWIR L2 version 01.xx retrieval results.

ISSUE-1: the minimum of the mean-squared value of the residual (Eq. 1) of TANSO-FTS Band 1 increased with time (Fig. 2a), probably owing to the changes in the baseline shape (continuum) of the residual spectrum (Fig. 2b).

$\chi^{2}=\frac{[\boldsymbol{y}-\boldsymbol{F}(\boldsymbol{x})]^{T} \mathbf{S}_{\varepsilon}^{-1}[\boldsymbol{y}-\boldsymbol{F}(\boldsymbol{x})]}{m}$

where $\boldsymbol{y}$ is the measured spectrum, $\boldsymbol{F}(\boldsymbol{x})$ is a forward model, $\mathbf{S}_{\varepsilon}$ is the error covariance matrix, and $m$ is a number of channels. Note that the systematic structures in the residual spectra are probably due to the shortcoming of the spectroscopy of oxygen, because other GOSAT retrieval algorithm and retrieval using another instrument show similar residuals (e.g., Fig. 6 of Crisp et al., 2012). (a)

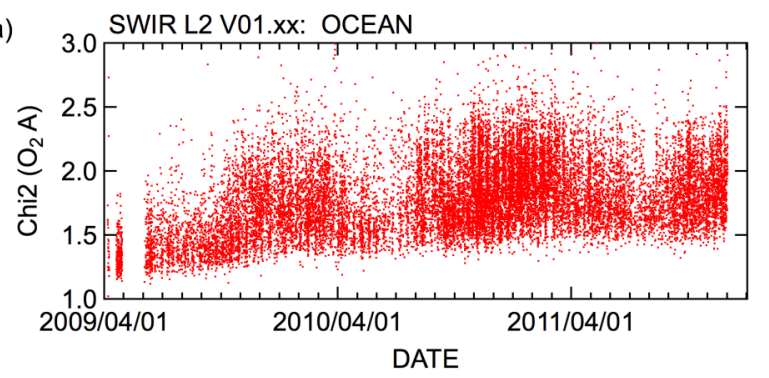

(b)

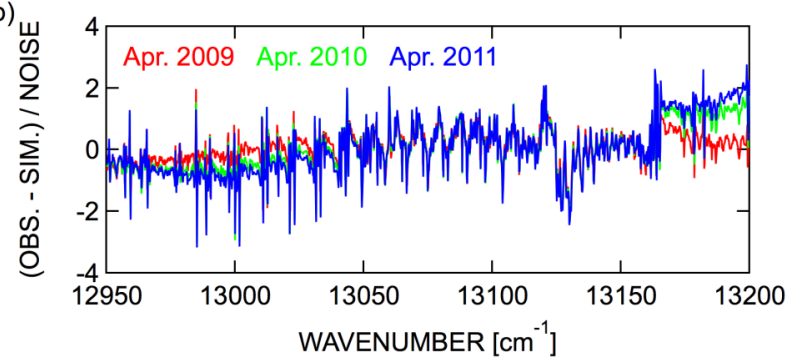

(c)

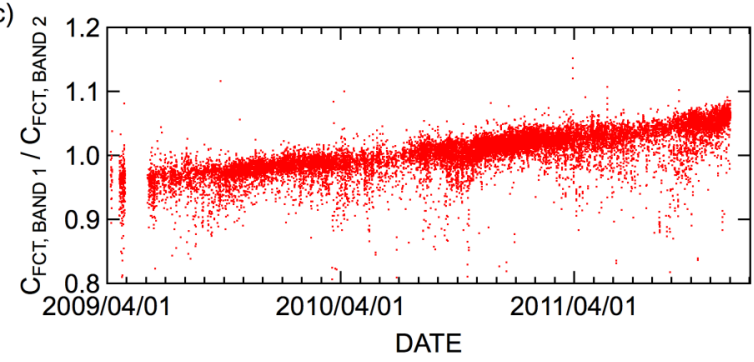

Fig. 2. Time-dependent issues found in the SWIR L2 version 01.xx retrieval. Ocean data were plotted. (a) Mean-squared value of the TANSO-FTS Band 1 residuals, (b) residual spectra of TANSO-FTS Band 1 for different years, and (c) ratio between the retrieved radiance adjustment factors.

ISSUE-2: the ratio between the radiance adjustment factor of Band 1 and that of Band 2 (see below for definition) changed with time (Fig. 2c).

Both issues were seen only for the ocean cases. In the SWIR L2 version 01.xx retrieval, the handling of the surface reflectance was different for land and ocean cases (Yoshida et al., 2011). Rough spectral structure of ground surface albedo in each band, which was represented by several grid-point values and varied linearly from one grid to the next, were retrieved for the land case, whereas the surface wind speed and radiance adjustment factor were retrieved for the ocean case. A water surface reflectance was calculated based on the slope probability distribution function proposed by Cox and Munk (1954). This assumption provides the water surface reflectance over the entire spectral range with a single parameter of surface wind speed. Because the SWIR L2 version 01.xx retrieval utilizes both Band 1 and 2 spectra, one surface wind speed parameter cannot represent the reflectance levels of the entire TANSO-FTS spectral range if the relative accuracy of the degradation between these bands is inaccurate. 
Table 1. On-orbit solar calibration data observed with the back-side diffuser plate, corresponding Sun-Earth-satellite angle $\theta_{\text {SES }}$ (see Fig. 3), and incident angle to the diffuser plate $\theta$. On 30 July 2009, no suitable data were available.

\begin{tabular}{|c|c|c|c|}
\hline $\begin{array}{l}\text { YYYY/MM/DD } \\
\text { hh:mm hh:mm }\end{array}$ & $\begin{array}{r}\text { Day after } \\
\text { launch }\end{array}$ & $\begin{array}{l}\text { Range of } \\
\theta_{\text {SES }} \text { [deg.] }\end{array}$ & $\begin{array}{r}\theta \text { [deg.] } \\
\left(\theta_{\mathrm{SES}} \approx 105\right)\end{array}$ \\
\hline 2009/03/04 13:51 13:59 & 40 & $122.1 \sim 95.6$ & 33.0 \\
\hline $2009 / 03 / 0415: 30 \sim 15: 37$ & 40 & $122.1 \sim 95.6$ & 41.1 \\
\hline 2009/03/04 18:46 18:53 & 40 & $122.0 \sim 95.6$ & 26.2 \\
\hline $2009 / 04 / 2903: 28 \sim 03: 32$ & 96 & $105.6 \sim 91.9$ & 32.0 \\
\hline 2009/06/28 03:25 03:29 & 156 & $105.9 \sim 92.1$ & 32.3 \\
\hline 2009/07/01 03:25 03:29 & 159 & $105.8 \sim 92.0$ & 32.5 \\
\hline $2009 / 07 / 3022: 32 \sim 22: 35$ & 188 & $104.7 \sim 91.9$ & N/A \\
\hline $2009 / 08 / 2922: 34 \sim 22: 38$ & 218 & $105.8 \sim 91.9$ & 33.7 \\
\hline $2009 / 09 / 2822: 37 \sim 22: 41$ & 248 & $105.9 \sim 92.1$ & 33.4 \\
\hline $2009 / 10 / 2822: 40 \sim 22: 44$ & 278 & $105.9 \sim 92.1$ & 34.4 \\
\hline $2009 / 11 / 2722: 42 \sim 22: 46$ & 308 & $106.1 \sim 92.1$ & 37.3 \\
\hline $2009 / 12 / 2722: 43 \sim 22: 46$ & 338 & $106.2 \sim 92.1$ & 40.7 \\
\hline $2010 / 01 / 2622: 41 \sim 22: 45$ & 368 & $106.0 \sim 91.9$ & 42.0 \\
\hline $2010 / 02 / 2522: 38 \sim 22: 42$ & 398 & $106.1 \sim 92.0$ & 39.9 \\
\hline $2010 / 03 / 2722: 35 \sim 22: 39$ & 428 & $107.1 \sim 93.1$ & 35.8 \\
\hline $2010 / 04 / 2622: 32 \sim 22: 36$ & 458 & $107.0 \sim 93.2$ & 32.4 \\
\hline $2010 / 05 / 2622: 30 \sim 22: 34$ & 488 & $105.5 \sim 91.8$ & 31.4 \\
\hline $2010 / 06 / 2522: 30 \sim 22: 34$ & 518 & $106.3 \sim 92.0$ & 32.3 \\
\hline $2010 / 07 / 2522: 31 \sim 22: 35$ & 548 & $106.4 \sim 92.6$ & 33.5 \\
\hline $2010 / 08 / 2722: 33 \sim 22: 37$ & 581 & $108.1 \sim 94.3$ & 33.6 \\
\hline $2010 / 09 / 2622: 37 \sim 22: 41$ & 611 & $105.8 \sim 92.1$ & 33.3 \\
\hline $2010 / 10 / 2622: 41 \sim 22: 45$ & 641 & $106.1 \sim 92.4$ & 34.1 \\
\hline $2010 / 11 / 2522: 43 \sim 22: 47$ & 671 & $105.9 \sim 92.1$ & 36.8 \\
\hline $2010 / 12 / 2522: 44 \sim 22: 47$ & 701 & $107.6 \sim 97.3$ & 40.2 \\
\hline $2011 / 01 / 2422: 43 \sim 22: 45$ & 731 & $108.0 \sim 97.6$ & 41.7 \\
\hline $2011 / 02 / 2322: 41 \sim 22: 44$ & 761 & $105.9 \sim 95.6$ & 39.7 \\
\hline $2011 / 03 / 2522: 38 \sim 22: 41$ & 791 & $107.3 \sim 97.1$ & 35.6 \\
\hline $2011 / 04 / 2722: 35 \sim 22: 38$ & 824 & $105.6 \sim 95.5$ & 31.7 \\
\hline $2011 / 05 / 2722: 33 \sim 22: 36$ & 854 & $107.7 \sim 97.7$ & 30.7 \\
\hline $2011 / 06 / 2622: 33 \sim 22: 36$ & 884 & $105.8 \sim 95.7$ & 31.7 \\
\hline $2011 / 08 / 2522: 37 \sim 22: 40$ & 944 & $105.6 \sim 95.5$ & 32.9 \\
\hline $2011 / 09 / 2722: 40 \sim 22: 43$ & 977 & $106.4 \sim 96.3$ & 32.6 \\
\hline $2011 / 10 / 2722: 43 \sim 22: 45$ & 1007 & $107.8 \sim 97.7$ & 33.6 \\
\hline $2011 / 11 / 2622: 45 \sim 22: 48$ & 1037 & $105.8 \sim 95.6$ & 36.5 \\
\hline
\end{tabular}

The radiance adjustment factor adjusts the radiance level between the bands to avoid a retrieval failure. ISSUE- 1 can be explained if the Band 1 degradation has a wavenumber dependency, and ISSUE-2 is directly related to the accuracy of the degradation.

\section{On-orbit solar calibration}

The solar radiation reflected by the onboard Spectralon diffuser plate is introduced into the TANSO-FTS when the satellite passes over the northern polar region. Except for the diffuser plate, the optical path inside the TANSO-FTS instrument is the same for both Earth observation (nadir, sunglint, and target) and solar calibration (see Fig. 1 of Kuze et al., 2012). Around $35 \sim 50$ scans (about $3 \sim 4$ min converted into the data acquisition time) of solar calibration data were obtained for each orbit (Fig. 3). Both sides of the diffuser plate are used for the solar calibration; the front side is

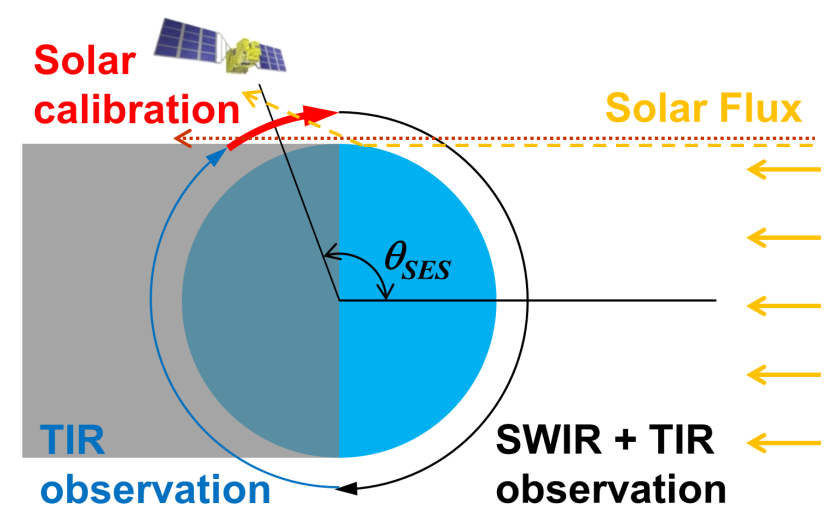

Fig. 3. On-orbit operation of GOSAT. Solar calibration is conducted when the satellite passes over the northern polar region. Dotted and dashed lines are possible optical paths when observed solar radiation is contaminated by the terrestrial atmospheric absorption.

usually exposed to direct solar radiation and the back side is exposed only once a month (Kuze et al., 2011).

In this study, we used the solar calibration data taken with the back side diffuser plate, because it is expected to have suffered less degradation than the front side diffuser (Kuze et al., 2012). Table 1 summarizes the solar calibration data observed by the back side diffuser plate. The solar calibration data which were contaminated by weak absorption of the terrestrial atmosphere should be discarded. When the Sun-Earth-satellite angle $\theta_{\text {SES }}$ (see Fig. 3) is large, TANSO-FTS may receive a solar radiation directly transmitted through the terrestrial atmosphere (dotted line of Fig. 3). Also, TANSO-FTS may receive a solar radiation reflected/scattered by Earth's surface/atmosphere as a stray light, because an aperture of TANSO-FTS always faces to the nadir direction (dashed-line of Fig. 3). The former/latter effect becomes large when $\theta_{\text {SES }}$ is large/small. Except for the case of 4 March 2009, solar calibration data were obtained during the GOSAT passing the latter-half part of the red-arc

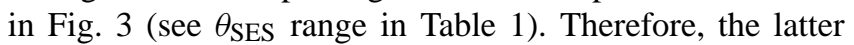
contamination was expected to be dominant. To discover the fine absorption structure, the observed solar spectra were averaged over certain $\theta_{\text {SES }}$ regions and then their differences were checked (Fig. 4). The absorption structure due to terrestrial atmospheric molecular oxygen can be seen when $\theta_{\text {SES }}$ is smaller than about 105 degrees probably due to the contamination of the reflected/scattered light. By also considering the data availability (see the range of $\theta_{\text {SES }}$ in Table 1 ), we used the data with $\theta_{\text {SES }}$ just above 105 degrees for each solar calibration in the following analysis.

The general formula of the spectrum observed by TANSOFTS was a function of the pointing mirror direction. It was expressed as a product of several Mueller matrices (e.g., pointing mirror, TANSO-FTS-mechanism, after-optics, rotation according to the pointing mirror angle, etc.; hereafter called optical efficiency) and a Stokes vector of the incident 


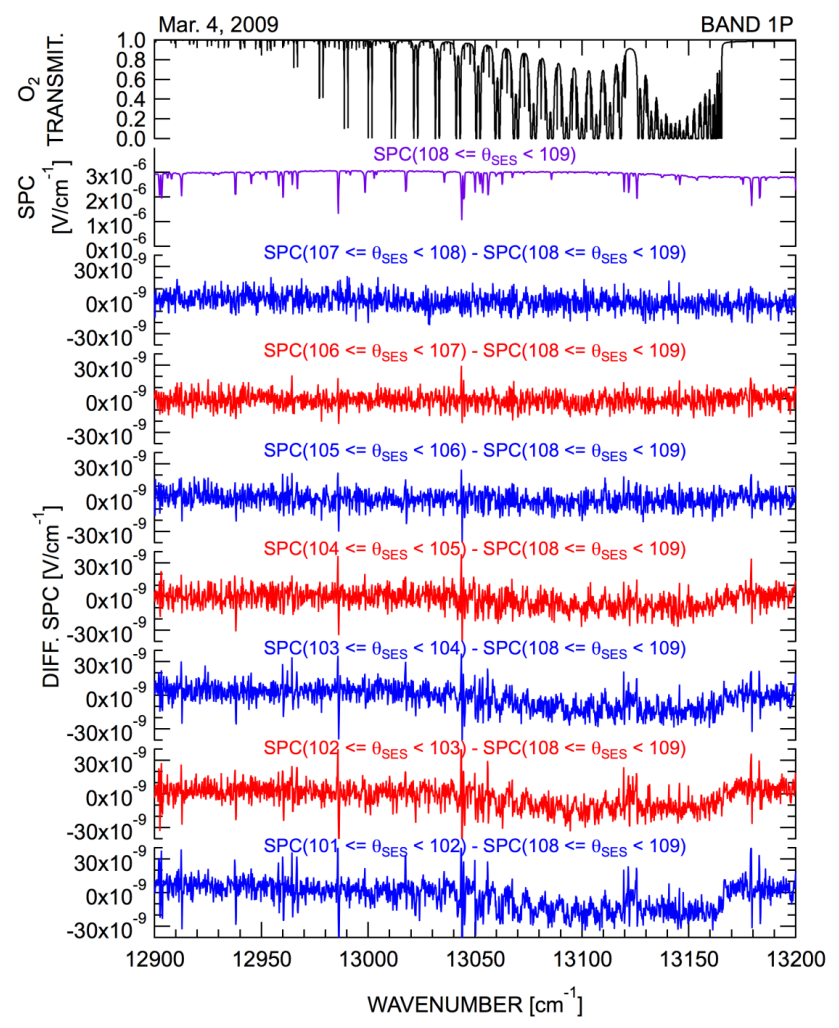

Fig. 4. An example of the averaged solar spectrum over the specified

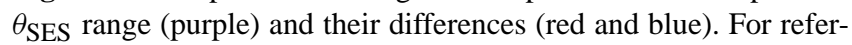
ence, transmittance of the terrestrial atmospheric oxygen (black) is also shown.

light (Eqs. 9 and 10 of Kuze et al., 2012). Because the pointing mirror pointed to the diffuser plate and did not move during the solar calibration, the optical efficiency of TANSOFTS becomes only a function of wavenumber $v$. To express the solar calibration data, we have to consider the reflection at the diffuser plate. Since we assume that the back side diffuser plate has not been degraded, the diffuser plate reflectance $r$ is a function of $v$ and incident and relative azimuth angles to the diffuser plate ( $\theta$ and $\phi$, respectively). Furthermore, the temporal variation of the solar flux due to the Earth's revolution is considered. The observed spectrum $S$ of the solar calibration can be expressed as

$$
\begin{aligned}
S_{\mathrm{P} / \mathrm{S}}(v, \theta, \phi, t)= & \frac{F_{\mathrm{SUN}}(v) \cos \theta}{\pi R(t)^{2}} r_{\mathrm{P} / \mathrm{S}}(v, \theta, \phi) \\
& \operatorname{OPT}_{\mathrm{P} / \mathrm{S}}(v) A_{\mathrm{P} / \mathrm{S}}(v, t),
\end{aligned}
$$

where $t$ is a day after the launch (i.e., $t=0$ for 23 January 2009); $F_{\text {SUN }}$ is the solar irradiance; $R$ is the distance between Sun and Earth in astronomical units; OPT is the optical efficiency of the TANSO-FTS without diffuser plate; $A$ is the radiometric degradation of TANSO-FTS; and subscripts "P" and " $\mathrm{S}$ " indicate the polarization components. (a)

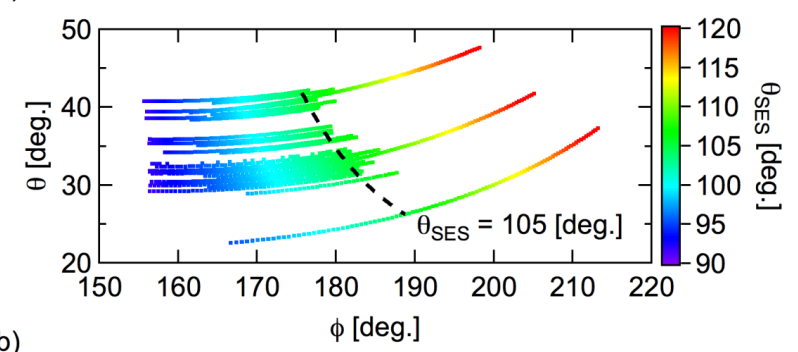

(b)

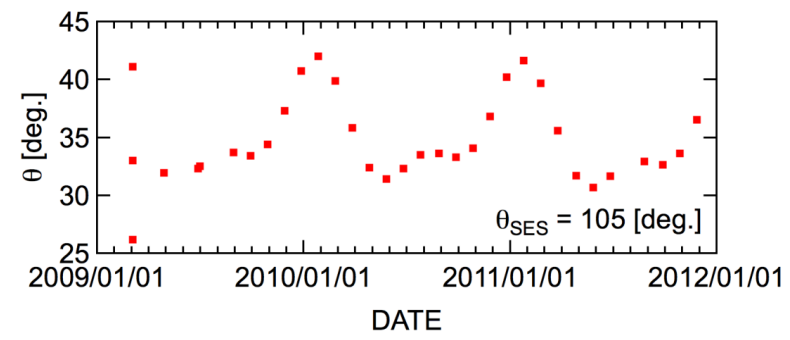

Fig. 5. (a) Relationship between the incident angle and relative azimuth angle of solar radiation to the diffuser plate. (b) The incident angle of solar radiation to the diffuser plate for $\theta_{\mathrm{SES}} \approx 105$ degree cases.

\section{Evaluation of the radiometric degradation of TANSO-FTS}

\subsection{Incident angle dependency of the diffuser plate}

Figure 5a shows the relationship between $\theta$ and $\phi$ for the solar calibration data observed by the back-side diffuser plate. Each curve corresponds to a single solar calibration. Because the requirement $\theta_{\mathrm{SES}} \approx 105 \mathrm{deg}$. determines the relationship between $\theta$ and $\phi$ uniquely, $\phi$ is omitted hereafter. To obtain the $\theta$ dependency of the diffuser plate reflectance, a special solar calibration was conducted on 4 March 2009 $\left(t=t_{0}=40\right)$ by rotating the whole satellite (corresponding to the three uppermost data in Table 1 and the three longest curves in Fig. 5a; Kuze et al., 2012). In this case, Eq. (2) can be written as

$$
\frac{S_{\mathrm{P} / \mathrm{S}}\left(\nu, \theta, t_{0}\right)}{r_{\mathrm{P} / \mathrm{S}}(\nu, \theta) \cos \theta}=\frac{F_{\mathrm{SUN}}(v)}{\pi R\left(t_{0}\right)^{2}} \mathrm{OPT}_{\mathrm{P} / \mathrm{S}}(v) A_{\mathrm{P} / \mathrm{S}}\left(v, t_{0}\right) .
$$

The right hand side of Eq. (3) is only a function of wavenumber. Therefore, the diffuser plate reflectance normalized by the reference reflectance observed at $\theta_{0}$ becomes

$\frac{r_{\mathrm{P} / \mathrm{S}}(v, \theta)}{r_{\mathrm{P} / \mathrm{S}}\left(v, \theta_{0}\right)}=\frac{\cos \theta_{0}}{\cos \theta} \frac{S_{\mathrm{P} / \mathrm{S}}\left(v, \theta, t_{0}\right)}{S_{\mathrm{P} / \mathrm{S}}\left(v, \theta_{0}, t_{0}\right)}$.

In this study, the uppermost data in Table 1 was selected as the reference spectrum; i.e., $\theta_{0}=33$ degree. If the diffuser plate is Lambertian, Eq. (4) becomes unity; however, it showed clear $\theta$ dependency (Fig. 6). To make a diffuser plate reflectance model, the observed spectrum was first fitted 
Table 2. Coefficients $a, b$, and $c$ of (a) Band 1, (b) Band 2, and (c) Band 3 to model the reflectance of the diffuser plate as a function of incident angle.

\begin{tabular}{lrrrrrrr}
\hline \multirow{2}{*}{$\begin{array}{l}\text { Wavenumber } \\
{\left[\mathrm{cm}^{-1}\right]}\end{array}$} & $a$ & $b$ & $c$ & & \multicolumn{3}{c}{ S-polarization } \\
\cline { 2 - 5 } \cline { 6 - 8 } (a) & & & & & $b$ & $c$ \\
12850 & -1.013 & 1.411 & 0.529 & & -0.714 & 0.994 & 0.668 \\
12950 & 0.119 & -0.451 & 1.294 & & 0.020 & -0.197 & 1.151 \\
13050 & 0.102 & -0.418 & 1.279 & & 0.076 & -0.292 & 1.192 \\
13150 & -0.173 & 0.040 & 1.080 & & -0.087 & -0.008 & 1.068 \\
13250 & 0.830 & -1.602 & 1.760 & & 1.092 & -1.950 & 1.868 \\
\hline (b) & & & & & & & \\
5750 & -0.004 & -0.325 & 1.276 & & -0.207 & 0.138 & 1.023 \\
5850 & 0.121 & -0.526 & 1.356 & & 0.187 & -0.507 & 1.294 \\
5950 & 0.098 & -0.487 & 1.339 & & 0.091 & -0.346 & 1.226 \\
6050 & 0.038 & -0.389 & 1.299 & & 0.070 & -0.313 & 1.213 \\
6150 & 0.076 & -0.449 & 1.323 & & 0.084 & -0.341 & 1.227 \\
6250 & 0.109 & -0.507 & 1.348 & & 0.076 & -0.327 & 1.221 \\
6350 & 0.080 & -0.457 & 1.327 & & 0.106 & -0.378 & 1.243 \\
6450 & 0.328 & -0.865 & 1.495 & & 0.275 & -0.664 & 1.363 \\
\hline (c) & & & & & & \\
4750 & -0.092 & -0.234 & 1.252 & & -0.244 & 0.191 & 1.012 \\
4850 & -0.090 & -0.223 & 1.250 & & 0.113 & -0.409 & 1.264 \\
4950 & -0.029 & -0.323 & 1.291 & & 0.148 & -0.457 & 1.279 \\
5050 & -0.103 & -0.185 & 1.228 & & 0.062 & -0.314 & 1.220 \\
5150 & -0.211 & -0.004 & 1.152 & & -0.178 & 0.088 & 1.052 \\
5250 & -0.296 & 0.139 & 1.091 & & -0.025 & -0.173 & 1.162 \\
\hline & & & & & & &
\end{tabular}
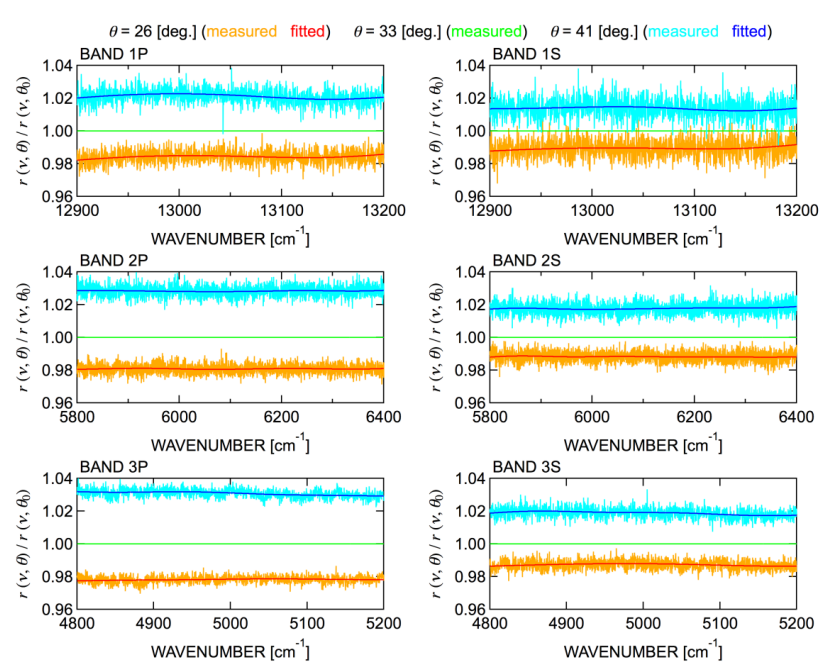

Fig. 6. Incident angle dependency of the reflectance spectrum of the diffuser plate. Plotted data is normalized with the reference reflectance spectrum obtained at $\theta_{0}=33$ [deg.], therefore, green line $(\theta=33$ [deg.]) becomes unity. Orange and light blue lines show the measured data, while red and blue lines show the fitted spectra (Eq. 5).

by a cubic-spline curve. Then, the $\theta$ dependency was evaluated at each wavenumber point. The diffuser plate reflectance was assumed to be expressed as a second-order polynomial of $\cos \theta$, although the validity of this assumption could not be confirmed because of the insufficient number of incident angles.
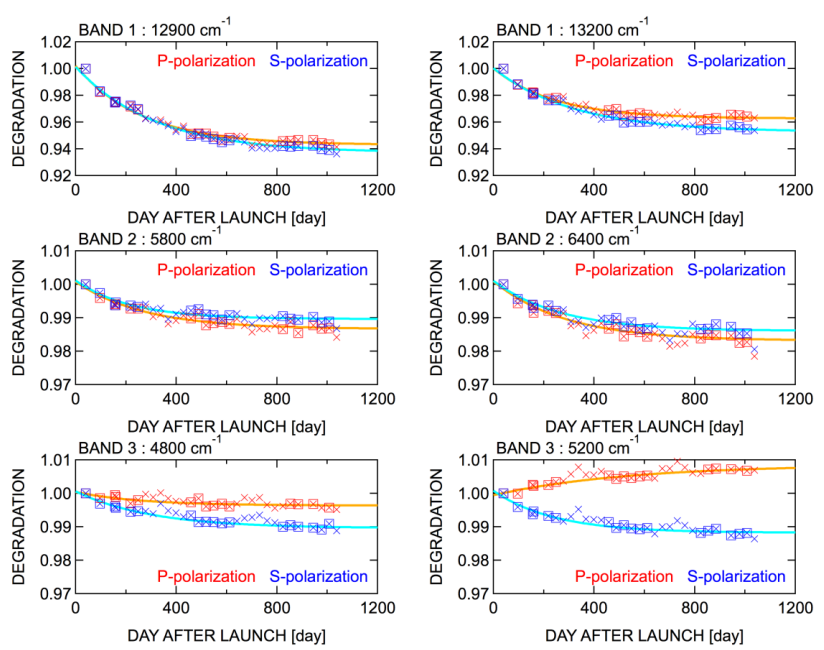

Fig. 7. Radiometric degradation of TANSO-FTS evaluated from the on-orbit solar calibration data (crosses). For curve fitting (Eq. 7), data observed with the incident angle less than 35 degree (squares) were used.

$\frac{r_{\mathrm{P} / \mathrm{S}}(v, \theta)}{r_{\mathrm{P} / \mathrm{S}}\left(v, \theta_{0}\right)} \approx a_{\mathrm{P} / \mathrm{S}}(v) \cos ^{2} \theta+b_{\mathrm{P} / \mathrm{S}}(v) \cos \theta+c_{\mathrm{P} / \mathrm{S}}(v)$.

The evaluated coefficients $a, b$, and $c$ are summarized in Table 2 .

\subsection{Radiometric degradation of TANSO-FTS}

From Eq. (2), the relative degradation of TANSO-FTS can be written as

$$
\begin{aligned}
\frac{A_{\mathrm{P} / \mathrm{S}}(v, t)}{A_{\mathrm{P} / \mathrm{S}}\left(v, t_{0}\right)}= & \frac{R(t)^{2}}{R\left(t_{0}\right)^{2}} \frac{\cos \theta_{0}}{\cos \theta} \frac{S_{\mathrm{P} / \mathrm{S}}(v, \theta, t)}{S_{\mathrm{P} / \mathrm{S}}\left(v, \theta_{0}, t_{0}\right)} \frac{r_{\mathrm{P} / \mathrm{S}}\left(v, \theta_{0}\right)}{r_{\mathrm{P} / \mathrm{S}}(v, \theta)} \\
\approx & \frac{R(t)^{2}}{R\left(t_{0}\right)^{2}} \frac{\cos \theta_{0}}{\cos \theta} \frac{S_{\mathrm{P} / \mathrm{S}}(v, \theta, t)}{S_{\mathrm{P} / \mathrm{S}}\left(v, \theta_{0}, t_{0}\right)} \\
& \frac{1}{a_{\mathrm{P} / \mathrm{S}}(v) \cos ^{2} \theta+b_{\mathrm{P} / \mathrm{S}}(v) \cos \theta+c_{\mathrm{P} / \mathrm{S}}(v)}
\end{aligned}
$$

The reference spectrum is the same as that in previous section; i.e., $t_{0}=40$ ( 4 March 2009) and $\theta_{0}=33$ degree. By performing a similar fitting process to that in the previous section, we evaluated the radiometric degradations of TANSOFTS at specific wavenumbers (Fig. 7). The degradation for each wavenumber point and polarization was modeled as

$$
\frac{A_{\mathrm{P} / \mathrm{S}}(v, t)}{A_{\mathrm{P} / \mathrm{S}}\left(v, t_{0}\right)}=d_{\mathrm{P} / \mathrm{S}}(v)+e_{\mathrm{P} / \mathrm{S}}(v) \exp \left[-f_{\mathrm{P} / \mathrm{S}}(v) \cdot t\right],
$$

where $d, e$, and $f$ are fitting coefficients. There were several periods that showed slightly larger deviations from the exponential form (Fig. 7). These periods corresponded to large incident angle $\theta$, perhaps owing to the assumption of a secondorder polynomial for the modeled $\theta$ dependency of the diffuser plate reflectance (Eq. 5). Here, data with $\theta$ larger than 
Table 3. Coefficients $d, e$, and $f$ of (a) Band 1, (b) Band 2, and (c) Band 3 to model the radiometric degradation of TANSO-FTS as a function of time.

\begin{tabular}{|c|c|c|c|c|c|c|c|}
\hline \multirow{2}{*}{$\begin{array}{l}\text { Wavenumber } \\
{\left[\mathrm{cm}^{-1}\right]}\end{array}$} & \multicolumn{3}{|c|}{ P-polarization } & \multicolumn{4}{|c|}{ S-polarization } \\
\hline & $d$ & $e$ & $f$ & $d$ & $e$ & $f$ & \\
\hline \multicolumn{8}{|l|}{ (a) } \\
\hline 12850 & 0.940 & $6.12 \times 10^{-2}$ & $3.85 \times 10^{-3}$ & & 0.938 & $6.48 \times 10^{-2}$ & $3.56 \times 10^{-3}$ \\
\hline 12900 & 0.943 & $5.91 \times 10^{-2}$ & $3.78 \times 10^{-3}$ & & 0.937 & $6.41 \times 10^{-2}$ & $3.18 \times 10^{-3}$ \\
\hline 12950 & 0.945 & $5.69 \times 10^{-2}$ & $3.84 \times 10^{-3}$ & & 0.939 & $6.22 \times 10^{-2}$ & $3.19 \times 10^{-3}$ \\
\hline 13000 & 0.934 & $6.61 \times 10^{-2}$ & $3.32 \times 10^{-3}$ & & 0.929 & $7.04 \times 10^{-2}$ & $2.86 \times 10^{-3}$ \\
\hline 13050 & 0.940 & $6.23 \times 10^{-2}$ & $3.61 \times 10^{-3}$ & & 0.934 & $6.73 \times 10^{-2}$ & $2.98 \times 10^{-3}$ \\
\hline 13100 & 0.940 & $6.29 \times 10^{-2}$ & $3.73 \times 10^{-3}$ & & 0.934 & $6.93 \times 10^{-2}$ & $3.09 \times 10^{-3}$ \\
\hline 13150 & 0.943 & $5.75 \times 10^{-2}$ & $3.44 \times 10^{-3}$ & & 0.934 & $6.47 \times 10^{-2}$ & $2.97 \times 10^{-3}$ \\
\hline 13200 & 0.963 & $3.74 \times 10^{-2}$ & $4.09 \times 10^{-3}$ & & 0.953 & $4.76 \times 10^{-2}$ & $3.15 \times 10^{-3}$ \\
\hline 13250 & 0.965 & $3.80 \times 10^{-2}$ & $5.15 \times 10^{-3}$ & & 0.957 & $4.54 \times 10^{-2}$ & $3.45 \times 10^{-3}$ \\
\hline \multicolumn{8}{|l|}{ (b) } \\
\hline 5750 & 0.987 & $1.52 \times 10^{-2}$ & $4.53 \times 10^{-3}$ & & 0.988 & $1.37 \times 10^{-2}$ & $4.78 \times 10^{-3}$ \\
\hline 5800 & 0.987 & $1.42 \times 10^{-2}$ & $3.65 \times 10^{-3}$ & & 0.990 & $1.15 \times 10^{-2}$ & $4.57 \times 10^{-3}$ \\
\hline 5850 & 0.986 & $1.48 \times 10^{-2}$ & $3.78 \times 10^{-3}$ & & 0.988 & $1.19 \times 10^{-2}$ & $3.71 \times 10^{-3}$ \\
\hline 5900 & 0.985 & $1.51 \times 10^{-2}$ & $3.64 \times 10^{-3}$ & & 0.988 & $1.23 \times 10^{-2}$ & $3.92 \times 10^{-3}$ \\
\hline 5950 & 0.986 & $1.40 \times 10^{-2}$ & $3.66 \times 10^{-3}$ & & 0.988 & $1.19 \times 10^{-2}$ & $3.58 \times 10^{-3}$ \\
\hline 6000 & 0.985 & $1.43 \times 10^{-2}$ & $2.91 \times 10^{-3}$ & & 0.987 & $1.26 \times 10^{-2}$ & $3.61 \times 10^{-3}$ \\
\hline 6050 & 0.986 & $1.43 \times 10^{-2}$ & $3.21 \times 10^{-3}$ & & 0.987 & $1.31 \times 10^{-2}$ & $3.59 \times 10^{-3}$ \\
\hline 6100 & 0.986 & $1.41 \times 10^{-2}$ & $3.35 \times 10^{-3}$ & & 0.987 & $1.25 \times 10^{-2}$ & $2.93 \times 10^{-3}$ \\
\hline 6150 & 0.987 & $1.40 \times 10^{-2}$ & $4.05 \times 10^{-3}$ & & 0.987 & $1.30 \times 10^{-2}$ & $4.02 \times 10^{-3}$ \\
\hline 6200 & 0.985 & $1.42 \times 10^{-2}$ & $2.64 \times 10^{-3}$ & & 0.987 & $1.31 \times 10^{-2}$ & $3.30 \times 10^{-3}$ \\
\hline 6250 & 0.985 & $1.57 \times 10^{-2}$ & $3.00 \times 10^{-3}$ & & 0.986 & $1.46 \times 10^{-2}$ & $3.13 \times 10^{-3}$ \\
\hline 6300 & 0.986 & $1.39 \times 10^{-2}$ & $3.40 \times 10^{-3}$ & & 0.987 & $1.25 \times 10^{-2}$ & $3.17 \times 10^{-3}$ \\
\hline 6350 & 0.984 & $1.67 \times 10^{-2}$ & $3.27 \times 10^{-3}$ & & 0.986 & $1.43 \times 10^{-2}$ & $3.42 \times 10^{-3}$ \\
\hline 6400 & 0.983 & $1.78 \times 10^{-2}$ & $3.51 \times 10^{-3}$ & & 0.986 & $1.50 \times 10^{-2}$ & $3.78 \times 10^{-3}$ \\
\hline 6450 & 0.982 & $2.01 \times 10^{-2}$ & $3.68 \times 10^{-3}$ & & 0.985 & $1.69 \times 10^{-2}$ & $4.95 \times 10^{-3}$ \\
\hline \multicolumn{8}{|l|}{ (c) } \\
\hline 4750 & 0.991 & $1.02 \times 10^{-2}$ & $5.88 \times 10^{-3}$ & & 0.985 & $1.53 \times 10^{-2}$ & $3.56 \times 10^{-3}$ \\
\hline 4800 & 0.996 & $4.06 \times 10^{-3}$ & $3.86 \times 10^{-3}$ & & 0.990 & $1.10 \times 10^{-2}$ & $3.33 \times 10^{-3}$ \\
\hline 4850 & 0.997 & $5.59 \times 10^{-3}$ & $1.54 \times 10^{-2}$ & & 0.990 & $1.07 \times 10^{-2}$ & $2.89 \times 10^{-3}$ \\
\hline 4900 & 0.996 & $5.96 \times 10^{-3}$ & $1.22 \times 10^{-2}$ & & 0.990 & $1.02 \times 10^{-2}$ & $3.84 \times 10^{-3}$ \\
\hline 4950 & 0.993 & $9.84 \times 10^{-3}$ & $7.76 \times 10^{-3}$ & & 0.990 & $1.05 \times 10^{-2}$ & $3.67 \times 10^{-3}$ \\
\hline 5000 & 0.994 & $7.13 \times 10^{-3}$ & $5.04 \times 10^{-3}$ & & 0.990 & $1.07 \times 10^{-2}$ & $3.95 \times 10^{-3}$ \\
\hline 5050 & 0.999 & $-9.53 \times 10^{-6}$ & $9.87 \times 10^{-4}$ & & 0.990 & $1.13 \times 10^{-2}$ & $4.75 \times 10^{-3}$ \\
\hline 5100 & 1.007 & $-8.80 \times 10^{-3}$ & $1.16 \times 10^{-3}$ & & 0.989 & $1.13 \times 10^{-2}$ & $2.90 \times 10^{-3}$ \\
\hline 5150 & 1.016 & $-1.78 \times 10^{-2}$ & $4.61 \times 10^{-4}$ & & 0.988 & $1.22 \times 10^{-2}$ & $4.48 \times 10^{-3}$ \\
\hline 5200 & 1.009 & $-9.13 \times 10^{-3}$ & $1.87 \times 10^{-3}$ & & 0.988 & $1.26 \times 10^{-2}$ & $4.13 \times 10^{-3}$ \\
\hline 5250 & 1.043 & $-5.46 \times 10^{-2}$ & $5.68 \times 10^{-3}$ & & 0.976 & $3.11 \times 10^{-2}$ & $7.37 \times 10^{-3}$ \\
\hline
\end{tabular}

35 degree were not used when the coefficients $d, e$, and $f$ were evaluated. The evaluated coefficients are summarized in Table 3. Figure 8 shows the TANSO-FTS degradation until the end of 2011 calculated from the evaluated degradation model in this study. These results are roughly consistent with those of Kuze et al. (2012). However, we obtained several new findings because they did not consider the wavenumber and polarization dependencies.
The sensitivity degraded exponentially for all bands except in the higher wavenumber region $\left(>5050 \mathrm{~cm}^{-1}\right)$ of Band $3 \mathrm{P}$, where our analysis shows that the sensitivity increases with time. The reason for this unexpected sensitivity increase was unclear. Among the GOSAT SWIR retrievals (Yoshida et al., 2011; Oshchepkov et al., 2011; Butz et al., 2011; Parker et al., 2011; Crisp et al., 2012; Schepers et al., 2012), none were used in this wavenumber region for greenhouse gas retrieval, although Yoshida et al. (2011) and Schepers et al. (2012) 

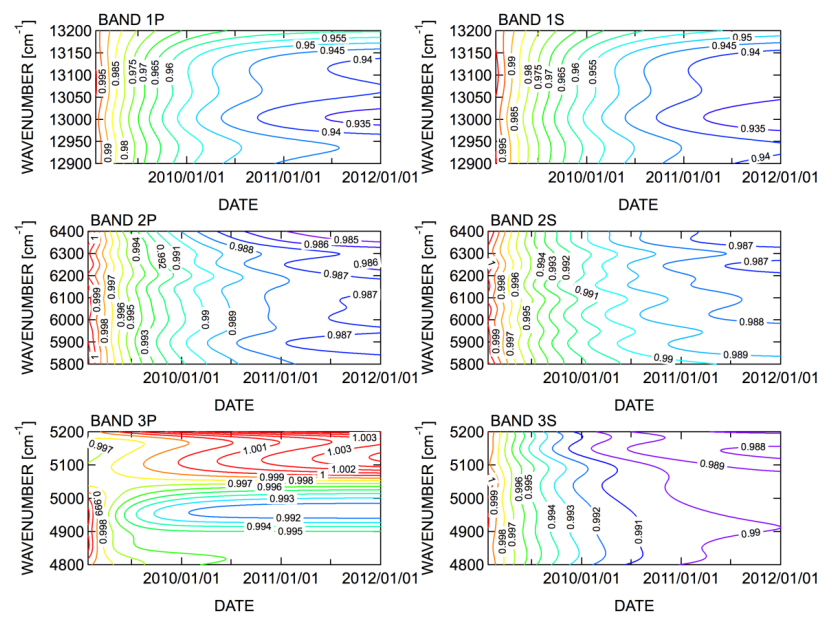

Fig. 8. The TANSO-FTS radiometric degradation in various spectral bands calculated from the radiometric degradation model evaluated in this study.

used the region for cirrus screening. Because both cirrus screening methods utilize the relationship between the observed signal level at this wavenumber region and the noise level, the priority of accurate radiometric calibration in this spectral range is not so high. Also, this spectral range cannot be calibrated using surface based vicarious calibration technics because of uncertainties in the water vapor absorption in the terrestrial atmosphere. Therefore, we do not discuss this Band 3P issue further in this paper.

The difference in degradation within the band was largest for Band $1(\sim 2 \%)$ and relatively small for Band 2 and $3 \mathrm{~S}$ ( $<$ $0.5 \%)$. For Band 1, the degradation of the higher wavenumber region $\left(>13150 \mathrm{~cm}^{-1}\right)$ was smaller than that of other wavenumber regions. Because the wavenumber-independent degradation correction was applied in the SWIR L2 version 01.xx retrieval, the observed Band 1 spectrum in this wavenumber region suffered excess degradation correction; i.e., the corrected spectrum showed a higher radiance level than the true level and the residual spectrum was expected to have positive value. This tendency coincided with ISSUE-1 (Fig. 2b). Although the actual time constants of degradation for all bands looked similar (about $0.7 \sim 0.9 \mathrm{yr}$; Table 3), the time constant of Band 1 used in the SWIR L2 version 01.xx retrieval was one-fifth that of Bands 2 and 3 (Fig. 1). To compensate this difference, the ratio of the retrieved radiance adjustment factor could be considered to change with time (ISSUE-2; Fig. 2c).

\subsection{Application of the improved degradation model}

Since Eq. (7) gives a radiometric degradation relative to the reference date, we should evaluate the absolute radiometric degradation. In this paper, we used the results of the vicarious calibration campaign (Table IV of Kuze et al., 2011). By substituting the mean value of the evaluated sensitivity-change (a)

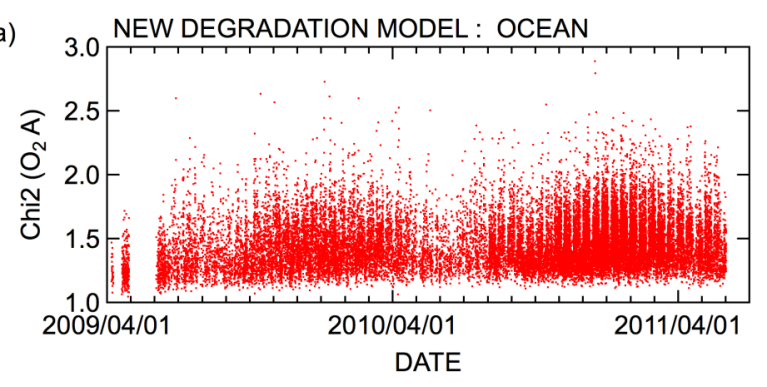

(b)

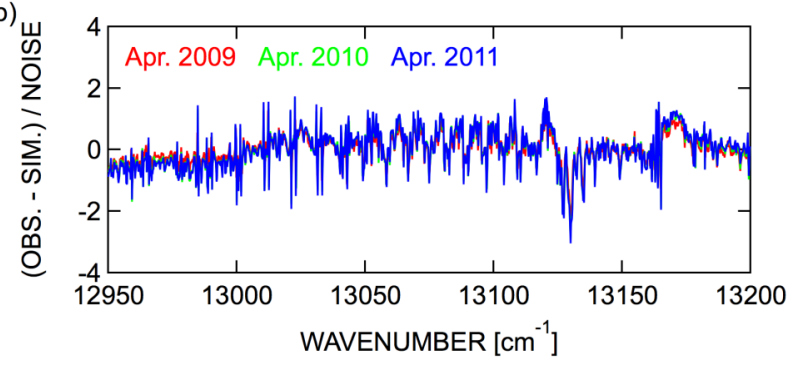

(c)

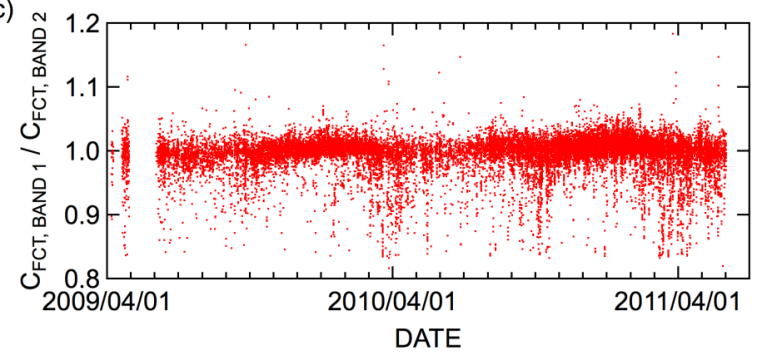

Fig. 9. Same as Fig. 2 except that the new degradation model evaluated in this study was used in this retrieval analysis.

relative to the pre-launch calibration data as an absolute degradation $A_{\mathrm{P} / \mathrm{S}}(v, t)(0.893,0.881,0.986,0.975,0.975$, and 0.963 for Band $1 \mathrm{P}, 1 \mathrm{~S}, 2 \mathrm{P}, 2 \mathrm{~S}, 3 \mathrm{P}$, and $3 \mathrm{~S}$, respectively) and $t=157$ (29 June 2009; mid-day of the campaign) into Eq. (7), we can calculate the absolute degradation at $t=t_{0}=40$ (4 March 2009) $A_{\mathrm{P} / \mathrm{S}}\left(v, t_{0}\right)$. Note that the absolute degradation at $t=0$ (23 January 2009) is not unity due to several reasons: (i) sensitivity-change between before and after the launch; (ii) fitting error of Eqs. (5) and (7); (iii) error in the pre-launch calibration data.

The degradation model is applied as follows. First, calculate the absolute degradation $A_{\mathrm{P} / \mathrm{S}}(v, t)$ of each wavenumber grid for a given observation date. Then, interpolate them to the target wavenumber by using a cubic spline. Finally, divide the interpolated absolute degradations into the observed spectra, and you get the radiometric calibrated spectra.

\subsection{Retrieval test using the evaluated degradation model}

We performed a retrieval test using the improved degradation model. Here, we focus on whether the time-dependent issues were solved or not. We do not discuss the retrieved $\mathrm{XCO}_{2}$ 
and $\mathrm{XCH}_{4}$ values in detail because this subject is beyond the scope of this paper, and the impact of the degradation correction on the retrieved $\mathrm{XCO}_{2}$ and $\mathrm{XCH}_{4}$ depends on the retrieval setting. Figure 9 shows the updated retrieval results. Both the minimum of the mean-squared value of the Band 1 residual and the ratio between the radiance adjustment factors flattened in time, and the Band 1 residual spectra for different years showed a similar baseline shape. Therefore, the root cause of the time-dependent issues in the SWIR L2 version 01.xx was concluded to be the accuracy of the degradation model. Difference in the retrieval results by using previous/improved degradation models changes with time, and difference in $\mathrm{XCO}_{2}$ and $\mathrm{XCH}_{4}$ for our retrieval (improved - previous) are about $-1.3 \mathrm{ppm} \mathrm{yr}^{-1}$ and $-6.7 \mathrm{ppb} \mathrm{yr}^{-1}$, respectively.

\section{Conclusions}

The radiometric degradation of TANSO-FTS was evaluated from the on-orbit solar calibration data. The radiometric sensitivity degraded exponentially for all bands except for the higher wavenumber region of Band 3P, and the time constant of degradation depended on the wavenumber and polarization. Band 1 showed the largest degradation (about $6 \%$ at the end of 2011) and had the largest wavenumber dependency within the bands. A new degradation model was constructed from the evaluated results. The predicted degradation after 2012 from this new degradation model is expected to be smaller than $1 \%$ for all bands. By applying the new degradation model to the retrieval, we eliminated the time-dependent issues seen in the SWIR L2 version 01.xx retrieval. The new degradation model is expected to suppress a possible timedependent bias error in the retrieval results.

Acknowledgements. The authors wish to thank H. Suto at JAXA for providing the TANSO-FTS on-orbit solar calibration data processed with the latest version of the operational Level 1 algorithm. Retrieval tests were conducted on the GOSAT Research Computation Facility. This research was supported in part by the Environment Research and Technology Development Fund (A-1102) of the Ministry of the Environment, Japan.

Edited by: M. Weber

\section{References}

Butz, A., Guerlet, S., Hasekamp, O., Schepers, D., Galli, A., Aben, I., Frankenberg, C., Hartmann, J.-M., Tran, H., Kuze, A., Keppel-Aleks, G., Toon, G., Wunch, D., Wennberg, P., Deutscher, N., Griffith, D., Macatangay, R., Messerschmidt, J., Notholt, J., and Warneke, T.: Toward accurate $\mathrm{CO}_{2}$ and $\mathrm{CH}_{4}$ observations from GOSAT, Geophys. Res. Lett., 38, L14812, doi:10.1029/2011GL047888, 2011.

Chevallier, F., Bréon, F.-M., and Rayner, P. J.: Contribution of the Orbiting Carbon Observatory to the estimation of
$\mathrm{CO}_{2}$ sources and sinks: Theoretical study in a variational data assimilation framework, J. Geophys. Res., 112, D09307, doi:10.1029/2006JD007375, 2007.

Chevallier, F., Maksyutov, S., Bousquet, P., Bréon, F.-M., Saito, R., Yoshida, Y., and Yokota, T.: On the accuracy of the $\mathrm{CO}_{2}$ surface fluxes to be estimated from the GOSAT observations, Geophys. Res. Lett., 36, L19807, doi:10.1029/2009GL040108, 2009.

Cox, C. and Munk, W.: Measurement of the roughness of the sea surface from photographs of the Sun's glitter, J. Opt. Soc. Am., 44, 838-850, 1954.

Crisp, D., Fisher, B. M., O’Dell, C., Frankenberg, C., Basilio, R., Bösch, H., Brown, L. R., Castano, R., Connor, B., Deutscher, N. M., Eldering, A., Griffith, D., Gunson, M., Kuze, A., Mandrake, L., McDuffie, J., Messerschmidt, J., Miller, C. E., Morino, I., Natraj, V., Notholt, J., O’Brien, D. M., Oyafuso, F., Polonsky, I., Robinson, J., Salawitch, R., Sherlock, V., Smyth, M., Suto, H., Taylor, T. E., Thompson, D. R., Wennberg, P. O., Wunch, D., and Yung, Y. L.: The ACOS $\mathrm{CO}_{2}$ retrieval algorithm - Part II: Global $X_{\mathrm{CO}_{2}}$ data characterization, Atmos. Meas. Tech., 5, 687707, doi:10.5194/amt-5-687-2012, 2012.

Hungershoefer, K., Breon, F.-M., Peylin, P., Chevallier, F., Rayner, P., Klonecki, A., Houweling, S., and Marshall, J.: Evaluation of various observing systems for the global monitoring of $\mathrm{CO}_{2}$ surface fluxes, Atmos. Chem. Phys., 10, 10503-10520, doi:10.5194/acp-10-10503-2010, 2010.

Kuze, A., Suto, H., Nakajima, M., and Hamazaki, T.: Thermal and near infrared sensor for carbon observation Fourier-transform spectrometer on the Greenhouse gases Observing Satellite for greenhouse gases monitoring, Appl. Optics, 48, 6716-6733, 2009.

Kuze, A., O’Brien, D. M., Taylor, T. E., Day, J. O., O’Dell, C. W., Kataoka, F., Yoshida, M., Mitomi, Y., Bruegge, C. J., Pollock, H., Basilio, R., Helmlinger, M., Matsunaga, T., Kawakami, S., Shiomi, K., Urabe, T., and Suto, H.: Vicarious Calibration of the GOSAT Sensors Using the Railroad Valley Desert Playa, IEEE T. Geosci. Remote, 49, 1781-1795, doi:10.1109/TGRS.2010.2089527, 2011.

Kuze, A., Suto, H., Shiomi, K., Urabe, T., Nakajima, M., Yoshida, J., Kawashima, T., Yamamoto, Y., and Kataoka, F.: Level 1 algorithms for TANSO on GOSAT: processing and onorbit calibrations, Atmos. Meas. Tech. Discuss., 5, 2959-3018, doi:10.5194/amtd-5-2959-2012, 2012.

O’Dell, C. W., Connor, B., Bösch, H., O’Brien, D., Frankenberg, C., Castano, R., Christi, M., Eldering, D., Fisher, B., Gunson, M., McDuffie, J., Miller, C. E., Natraj, V., Oyafuso, F., Polonsky, I., Smyth, M., Taylor, T., Toon, G. C., Wennberg, P. O., and Wunch, D.: The ACOS $\mathrm{CO}_{2}$ retrieval algorithm - Part 1: Description and validation against synthetic observations, Atmos. Meas. Tech., 5, 99-121, doi:10.5194/amt-5-99-2012, 2012.

Oshchepkov, S., Bril, A., Maksyutov, S., and Yokota, T.: Detection of optical path in spectroscopic space-based observations of greenhouse gases: Application to GOSAT data processing, J. Geophys. Res., 116, D14304, doi:10.1029/2010JD015352, 2011.

Parker, R., Boesch, H., Cogan, A., Fraser, A., Feng, L., Palmer, P. I., Messerschmidt, J. Deutscher, N., Griffith, D. W. T., Notholt, J., Wennberg, P. O., and Wunch, D.: Methane observations from the Greenhouse gases Observing SATellite: Comparison to groundbased TCCON data and model calculations, Geophys. Res. Lett., 38, L15807, doi:10.1029/2011GL047871, 2011. 
Rayner, P. J. and O'Brien, D. M.: The utility of remotely sensed $\mathrm{CO}_{2}$ concentration data in surface source inversions, Geophys. Res. Lett., 28, 175-178, 2001.

Schepers, D., Guerlet, S., Butz, A., Landgraf, J., Frankenberg, C., Hasekamp, O., Blavier, J.-F., Deutscher, N. M., Griffith, D. W. T., Hase, F., Kyro, E., Morino, I., Sherlock, V., Sussmann, R., and Aben, I.: Methane retrievals from Greenhouse gases Observing Satellite (GOSAT) shortwave infrared measurements: Performance comparison of proxy and physics retrieval algorithms, J. Geophys. Res., 117, D10307, doi:10.1029/2012JD017549, 2012.

Takagi, H., Saeki, T., Oda, T., Saito, M., Valsala, V., Belikov, D., Saito, R., Yoshida, Y., Morino, I., Uchino, O., Andres, R. J., Yokota, T., and Maksyutov, S.: On the Benefit of GOSAT Observations to the Estimation of Regional $\mathrm{CO}_{2}$ Fluxes, SOLA, 7, 161-164, doi:10.2151/sola.2011-041, 2011.
Yokota, T., Yoshida, Y., Eguchi, N., Ota, Y., Tanaka, T., Watanabe, H., and Maksyutov, S.: Global Concentrations of $\mathrm{CO}_{2}$ and $\mathrm{CH}_{4}$ Retrieved from GOSAT: First Preliminary Results, SOLA, 5, 160-163, doi:10.2151/sola.2009-041, 2009.

Yoshida, Y., Ota, Y., Eguchi, N., Kikuchi, N., Nobuta, K., Tran, H., Morino, I., and Yokota, T.: Retrieval algorithm for $\mathrm{CO}_{2}$ and $\mathrm{CH}_{4}$ column abundances from short-wavelength infrared spectral observations by the Greenhouse gases observing satellite, Atmos. Meas. Tech., 4, 717-734, doi:10.5194/amt-4-717-2011, 2011. 